\title{
PENGARUH FINANCIAL DISTRESS, AUDIT DELAY, PERGANTIAN MANAJEMEN DAN OPINI GOING CONCERN TERHADAP AUDITOR SWITCHING STUDI KASUS PADA PERUSAHAAN SEKTOR KEUANGAN YANG TERDAFTAR DI BURSA EFEK INDONESIA TAHUN 2014-2018
}

\author{
Ni Putu Ayu Rizky Pradnyawati ${ }^{1}$, I Made Wianto Putra ${ }^{2}$, Ni Putu Riasning ${ }^{3}$ \\ Program Studi Akuntansi \\ Fakultas Ekonomi dan Bisnis Universitas Warmadewa, Bali, Indonesia \\ Email : rizkypradnya@gmail.com
}

\begin{abstract}
ABSTRAK
Penilitian ini untuk membuktikan secara empiris pengaruh Financial Distress, Audit delay, Pergantian Manajemen dan Opini Going Concern terhadap Auditor switching di Perusahaaan Sektor Keuangan yang ter-listing di BEI tahun 2014-2018. Metode pemilihaan sampel menerapkan metode purposive sampling dengan jenis data kuantitatif dan kualitatif serta sumber data sekunder. Metode pengumpulan data menerapkan metode dokumentasi serta teknik analisis data yakni analisis regresi logistik. Berdasarkan data dan pengujian diambil kesimpulan bahwa variabel financial distress dan audit delay tidak berpengaruh terhadap auditor switching, sementara pergantian manajemen dan opini going concern berpengaruh positif terhadap auditor swiching.
\end{abstract}

Kata Kunci: Financial Distress, Audit delay, Pergantian Manajemen, Opini Going Concern dan Auditor Switching

\begin{abstract}
This research is to empirically prove the influence of Financial Distress, Audit delay, Management Change and Going Concern Opinion on Auditor switching in Financial Sector Companies listed on the Indonesia Stock Exchange in 2014-2018. The sample selection method applies a purposive sampling method with quantitative and qualitative data types and secondary data sources. Data collection methods apply the method of documentation and data analysis techniques namely logistic regression analysis. Based on the data and testing, it can be concluded that the financial distress and audit delay variables have no effect on auditor switching, while management change and going concern opinion have a positive effect on auditor swiching.
\end{abstract}


Keywords: Financial Distress, Audit delay, Management Substitution, Going Concern Opinion and Auditor Switching

\section{A. Pendahuluan}

Profesi akuntan publik yang dicitakan masyarakatyakni penilaian yang netral kepada infornasi yamg disediakan oleh manajenen berupa finance report. Bertumbuhnya jumlah kantor akntan publik yang beroperasi bisa menjadikan persaingan antar KAP, sehinga bamyak yang berargumen untuk mengelak dari kompetisi. Rotasi audit ialah matter solver adanya kompetisi dalam perebutan pasar sektor jasa audit ditambah pula adanya kebijakan rotasi auditor yang seringnya menjadi kendala dalam mencari klien tetap dalam bisnis jasa ini.

Penilitian ini menakai perusahaaan sektor keuangan yang terdaftar di BEI tahun 2014-2018 sebagai objek penelitian. Selain diawasi oleh BEI, sektor keuangan juga mendapat pengawasan khusus dari Otoritas Jasa Keuangan (OJK) sehingga kebijakannya lebih ketat dan apabila terjadi pelanggaran akan dapat dideteksi lebih dini, serta prinsip keberlangsungan usaha yang lebih terjamin.

Berdasarkan ketidakkonsitenan hasil dari penilitian sebelumnya yang disebabkan oleh berbagai faktor, maka penilitian ini ingin melakukan konfirmasi atas penelitian-penelitian sebelumnya yang kemudian menguji beberapa faktor yang mempemgaruhi audittor switching dengan menganbil judul "Pengaruh Financial Distress, Audit delay, Pergantian Manajemen dan Opini Going Concern terhadap Auditor switching Studi Kasus pada Perusahaan Sektor Keuangan yang terdaftar di Bursa Efek Indonesia tahun 2014-2018”.

\section{B. Tinjauan Pustaka}

\section{a. Landasan Teori}

\section{Teori Agency}

Teori ini menerangkan bahwa adanya korelasi diantara pihak pemilik dengan pihak agen (manager). Hal ini menerangkan adanya sebuah kesepakatan dimana agen akan melaksanakan kegiatan operasional bisnis sang pemilik usaha yang akan disampaikan dalam bentuk laporan sebagai tanggung 
jawabnya kepada pihak principal.

\section{Audittor Switching}

Auditor Switching diartikan sebegai rotasi audittor secara berkala yang dilaksanakan oleh emiten untuk mengurangi adanya tindak fraud pada perusahaan.

\section{Financial Distress}

Hal ini diartikan dengan situasi sulit yang dialami perushaaan yang mana perusahaan tidak dapat untuk memenuhi kewajibannya saat ini. Pada situasi seperti ini biasanya pihak perusahaan akan mencari seorang auditor manajemen untuk menyehatkan kembali perusahaan.

4. Audit delay

Audit delay yakni keterlambatan selesainya pelaksanaan audit yang telah ditentukan sebelumnya untuk memperoleh bukti-bukti audit untuk dibuatkan laporan audit dalam penyampaian opini audit ke perusahaan yang bersangkutan.

\section{Pergantian Manajemen}

Pergantian manajemen diartikan dengan pergantian dewan direksi pada saat RUPS (Rapat Umum Pemegang Saham) yang disebabkan adanya kasus dan skandal yang menimpa direksi, pensiun, meninggal dan lain-lain. Perubahan tersebut tentu akan berdampak kepada perubahaan kebijakan-kebijakan keuangan perusahaan.

\section{Going Concern Audit Opinion}

Opinion ini yakni opini audit yang dihibahkan audit jika suatu perusahaaan sedang mengalami masa-masa krisis dan sangat sulit menentukan keberlangsungan hidup perusahaannya. Opini ini sangat rentan sekali membawa efek buruk bagi banyak pihak seperti masyarakat, karyawan dan lain-lain sehingga auditor sangat berhati-hati sekali dalam menyatakan opini ini kepada suatu perusahaan. 


\section{b. Kerangka Konsep \& Hipotesis Penelitian}

Pada penelitian ini, skema kerangka konsep untuk menjelaskan objek penilitian secara detail dapat digambarkan sebagai beirkut :

\section{Gambar 1.}

\section{Kerangka Konsep}

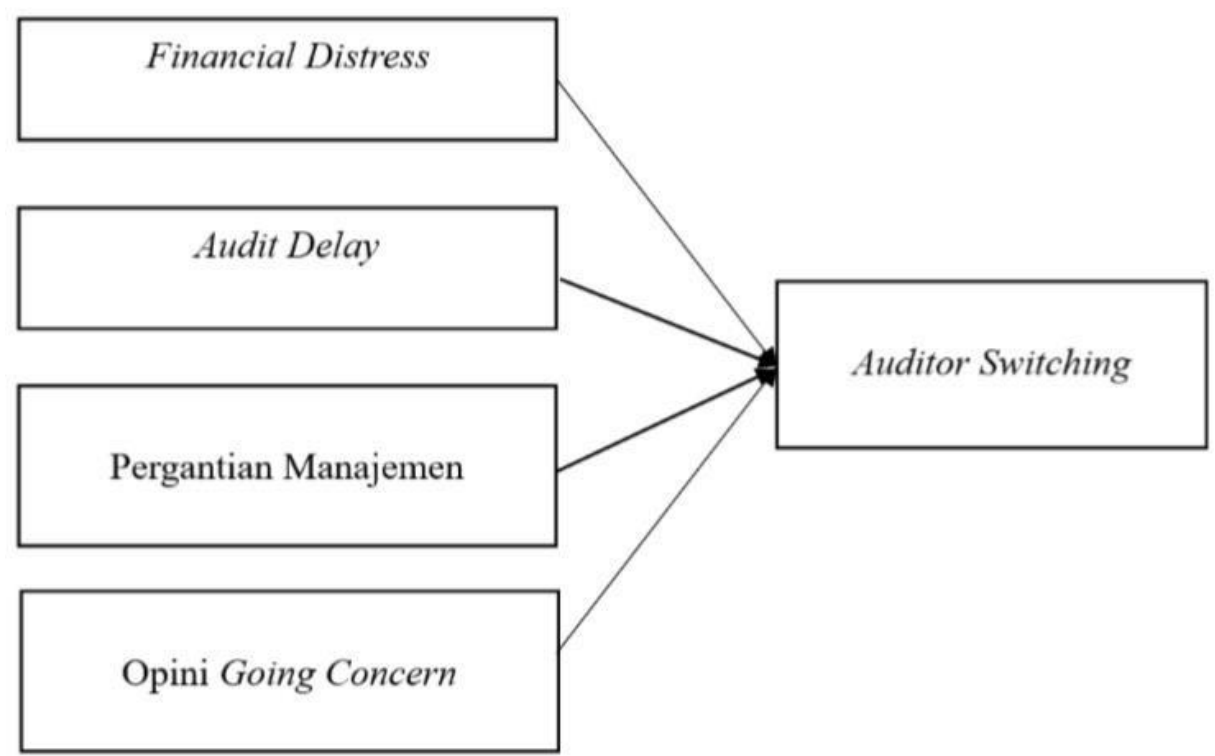

Selain itu, ada 4 hipotesis dalam penilitian ini yang dapat dibuatkan dengan table yang bisa dilihat sebagai berikut :

\section{Tabel 1.}

\section{Hipotesis Penelitian}

\begin{tabular}{|l|l|}
\hline H1 & Financial Distress tidak berpengaruh terhadap Auditor Switching \\
\hline H2 & Audit Delay tidak berpengaruh terhadap Auditor Switching \\
\hline H3 & Pergantian Manajemen berpengaruh positif terhadap Auditor Switching \\
\hline H4 & Opini Going Concern berpengaruh positif terhadap Auditor Switching \\
\hline
\end{tabular}




\section{METODE PENELITIAN}

Penilitian ini dijalankan pada perusahaaan sector keuamgan yamg terdaftar di BEI yangdapat diakses melalui http://idx.co.id. Penelitian ini memiliki jumlah populasi dengan jumlah 87 perusahaan dengan menggunakan metode purposive sampling sehingga memperoleh 25 perusahaan dan 5 tahun periode dengan demikian mendapatkan 125 data sampel penelitian. Penelitian ini menerapkan teknik analisis data yakni analisis regresi logistik.

\section{HASIL ANALISIS \& PEMBAHASAN}

\section{a. Uji Kelayakan Model Regresi}

Tabel 2.

Hasil Uji Hosmer and Lomeshow's Goodness of Fit Test

Hosmer and Lemeshow Test

\begin{tabular}{|l|r|r|c|}
\hline Step & Chi-square & \multicolumn{1}{c|}{ df } & Sig. \\
\hline 1 & 3,754 & 7 &, 808 \\
\hline
\end{tabular}

Sumber : Data diolah, 2020

Berdasarkan tabel2, dimaknai bahwa nilai statiktik Hosmerand Lomeshow's Goodnesss of FitTest ialah diperoleh Chi-square sebbesar 3,754 degan nilai signifikansebesar 0,808. Dengan demikian, hasil terrsebut nilaisignifikan 0,808>0,05 yang berarti modelregresi logistick dalan penilitian inilolos uji serta bisa dilanjutkan ke next step test.

\section{b. Menilai Model Fit}

Tabel 3.

Hasil Uji Overall Model -2 log Likehood (-2LL) Awal

\begin{tabular}{|c|c|c|}
\hline \multirow[b]{2}{*}{ Iteration } & \multirow{2}{*}{$\begin{array}{l}-2 \log \\
\text { likelihood }\end{array}$} & Coefficients \\
\hline & & Constant \\
\hline Step 0 & 172,638 &,- 144 \\
\hline & 172,638 &,- 144 \\
\hline
\end{tabular}

a. Constant is included in the model.

b. Initial - 2 Log Likelihood: 172,638

c. Estimation terminated at iteration number 2 because parameter estimates changed by less than ,001.

Sumber : Data diolah, 2020 
Menurut tabel diiatas bisa diilihat -2 LogLikelihood awal pada blocknumber $=$ 0 ,yaitu model hanya meng-input constant yang bisa diilihat pada step 2 yag menperoleh nilai sebesar 172,638.

Tabel 4.

Hasil Uji Overall Model -2 log Likehood (-2LL) Akhir Iteration History ${ }^{\mathrm{a}, \mathrm{b}, c, d}$

\begin{tabular}{|c|c|c|c|c|c|c|c|}
\hline \multirow{2}{*}{\multicolumn{2}{|c|}{ Iteration }} & \multirow{2}{*}{$\begin{array}{l}-2 \text { Log } \\
\text { likelihood }\end{array}$} & \multicolumn{5}{|c|}{ Coefficients } \\
\hline & & & Constant & $\mathrm{X} 1$ & $\times 2$ & $\times 3$ & $\times 4$ \\
\hline \multirow[t]{4}{*}{ Step 1} & 1 & 153,565 &, 271 & $-1,098$ &,- 276 & 1,078 & 1,047 \\
\hline & 2 & 153,234 &, 305 & $-1,182$ &,- 334 & 1,286 & 1,193 \\
\hline & 3 & 153,232 &, 306 & $-1,184$ &,- 338 & 1,305 & 1,202 \\
\hline & 4 & 153,232 &, 306 & $-1,184$ &,- 338 & 1,305 & 1,202 \\
\hline
\end{tabular}

a. Method: Enter

b. Constant is included in the model.

c. Initial -2 Log Likelihood: 172,638

d. Estimation terminated at iteration number 4 because parameter estimates changed by less than , 001 .

Sumber : Data diolah, 2020

Berdasarkan table di atas memperlihatkan nilai -2 log Likehood akhir adanya pengurangan nilai dari 172,638 menjadi 153,232 pada step 4 yang menandakan data sudah fit dan dapat dilanjutkan ke uji selanjutnya.

\section{c. Koefisien Determinasi}

Tabel 5.

Hasil Uji Model Summary

Model Summary

\begin{tabular}{|l|c|c|c|}
\hline Step & $\begin{array}{c}-2 \text { Log } \\
\text { likelihood }\end{array}$ & $\begin{array}{c}\text { Cox \& Snell R } \\
\text { Square }\end{array}$ & $\begin{array}{c}\text { Nagelkerke R } \\
\text { Square }\end{array}$ \\
\hline 1 & $153,232^{\mathrm{a}}$ &, 144 &, 192 \\
\hline
\end{tabular}

a. Estimation terminated at iteration number 4 because parameter estimates changed by less than , 001 .

Sumber : Data diolah, 2020 
Menurrut hasil uji Nagelkerke $R^{2}$, diperoleh nilai Nagelkerke $R^{2}$ sebesar 0,192. Hal ini berarti 19,20\% variasi auditor switching bisa diuraika noleh variasi variabel independen, antara lain Financial Distress, Audit delay, Pergantian Manajemen dan Opini Going Concern. Namun, sisanya sebesar $80,30 \%$ diterangkan oleh faktor lain diluar modelpenelitian.

\section{d. Model Regresi Logistik}

Hasil uji regrresi logistik yang bertujuuan untuk mengetahui pengaruh antar variabel bisa dilihat pada tabel beriktu:

Tabel 6.

Hasil Uji Regresi Logistik

Variables in the Equation

\begin{tabular}{|c|c|c|c|c|c|c|c|c|c|}
\hline & & \multirow[b]{2}{*}{ B } & \multirow[b]{2}{*}{ S.E. } & \multirow[b]{2}{*}{ Wald } & \multirow[b]{2}{*}{ df } & \multirow[b]{2}{*}{ Sig. } & \multirow[b]{2}{*}{$\operatorname{Exp}(B)$} & \multicolumn{2}{|c|}{$95 \%$ C.I.for EXP(B) } \\
\hline & & & & & & & & Lower & Upper \\
\hline \multirow[t]{5}{*}{ Step $1^{\mathbf{a}}$} & $\mathrm{X} 1$ & $-1,184$ &, 704 & 2,826 & 1 &, 093 & 306 & ,077 & 1,217 \\
\hline & $\times 2$ &,- 338 &, 441 & .585 & 1 & .445 & .714 &, 300 & 1,695 \\
\hline & $\times 3$ & 1,305 &, 655 & 3,969 & 1 &, 046 & 3,687 & 1,021 & 13,311 \\
\hline & $\times 4$ & 1,202 & .546 & 4,851 & 1 &, 028 & 3,328 & 1,142 & 9,700 \\
\hline & Constant &, 306 & .529 &, 335 & 1 &, 563 & 1,358 & & \\
\hline
\end{tabular}

a. Variable(s) entered on step $1: \times 1, \times 2, \times 3, \times 4$.

Sumber : Data diolah, 2020

\section{e. Pembahasan}

\section{Pengaruh Financial distress terhadap AuditorSwitching}

Hasil pengujian terhadap variabel financial distress memperlihatkan nilai koefisien regresi negatif sebesar $-1,184$ dengan tingkat signifikan 0,093>0,05, maka dalam perumusan $\mathrm{H} 1$ yang dihpotesiskan bahwa financial distress tidak berpengaruh terhadap auditor switching berhasilditerima. Dengan demikian dapat disimpulkan bahwa financial distress tidak berpengaruh terhadap auditor switching. 


\section{Pengaruh Audit delay terhadap AuditorSwitching}

Hasil pengujian terhadap variabel audit delay memperlihatkan nilai koefisien regresi negatif sebesar $-0,338$ dengan tingkat signifikan 0,445>0,05, maka dalam perumusan $\mathrm{H} 2$ yang dihpotesiskan bahwa audit delay tidak berpengaruh terhadap auditor switching berhasil diterima. Dengan demikian dapat disimpulkan bahwa audit delay tidak berpengaruh terhadap auditor switching.

\section{Pengaruh Pergantian Manajemen terhadap Auditor Switching}

Hasil pengujian terhadap variabel pergantian manajemen memperlihatkan nilai koefisien regresi positif sebesar 1,305 deengan tingkat signifikan 0,046<0,05, maka dalam perumusan H3 yang dihpotesiskan bahwa pergantian manajemen berpengaruh positif terhadap auditor switching berhasil diterima. Dengan demikian dapat disimpulkan bahwa pergantian manajemen berpengaruh positif terhadap auditor switching.

\section{Pengaruh Opini Going Concern terhadap AuditorSwitching}

Hasil pengujian terhadap variabel opini going concern memperlihatkan nilai koefisienregresi positif sebesar 1,202 dengan tingkat signifikan $0,028<0,05$, maka dalam perumusan $\mathrm{H} 4$ yang dihipotesiskan bahwa opini going concern berpengaruh positif terhadap auditor switching berhasil diterima. Dengan demikian dapat disimpulkan bahwa opini going concern berpengaruh positif terhadap auditor switching.

\section{E. PENUTUP}

\section{a. Simpulan}

Menurut uraian diiatas, maka dapat disimpulkan sebagai berikut.

1. Variabel financial distress tidak berpengaruh terhadap auditor switching.

2. Variabel audit delay tidak berpengaruh terhadap auditor switching.

3. Variabel pergantian manajemen berpengaruh positif terhadap auditor switching. 
4. Variabel opini going concern berpengaruh positif terhadap auditor swiching.

\section{b. Saran}

Adapun saran yang diberikan pada penelitian ini adalah sebagai berikut.

1. Bagi perusahaan sektor keuangan sebaiknyamenggunakan auditor sesuai dengan peraturan yang telah berlaku, karena itu berpengaruh terhadap penilaian masyarakat terhadap reputasi perusahaan itu sendiri.

2. Bagi calon investor sebaiknya sebelum melakukan investasi terlebih dahulu mengetahui informasi mengenai kinerja keuangan yang dihasilkan perusahaan khususnya dari segi financial distress. Karena dengan mengetahui informasi itu menjadikan bahan pertimbangan untuk menanamkkan sahamnya.

3. Bagi peneliti selanjutnya diharapkan menggunakan variabel-variabel independen lainnya seperti ukuran KAP, reputasi auditor, biaya audit dsb untuk mendapatkan hasil penelitian yang lebih detail.

\section{DAFTAR PUSTAKA}

Dura, J., \& Nuryatno. (2015). "Pengaruh Debt Default, Kualitas Audit, Opini Audit Tahun Sebelumnya, dan Audit Lag Terhadap Opini Audit Going Concern". Jurnal Magister Akuntansi Trisakti, 2(2), 145-160.

Edwin Wijaya, Ni Ketut Rasmini. (2015). "Pengaruh Audit Fee, Opini Going Concern, Financial Distress, Ukuran Perusahaan, Ukuran KAP Pada Pergantian Auditor". E-jurnal Akuntansi Universitas Udayana.11.3, 940- 966.

Ghozali, I. (2018). Aplikasi Analisis Multivariate Dengan Program IBM SPSS 19 (edisi kelima). Semarang: Universitas Diponegoro.

Gideon Saputra. (2017). "Pengaruh Opini Going Concern dan Pergantian Manajemen Terhadap Auditor switching, Reputasi Auditor Sebagai Variabel Moderating". JOM Fekom, Vol.4 No.1.

Herry,S.E.,M.Si.,CRP,.RSA.,CFRM. (2017). Teori Akuntansi Pendekatan Konsep dan Analisis). Jakarta: PT Grasindo, Anggota IKAPI.

Made Aditya Bayu Pradhana, I.D.G. Dharma Suputra. (2015). "Pengaruh Audit Fee, Going Concern, Financial Distress, Ukuran Perushaan, Pergantian Manajemen Pada Pergantian Auditor”. E-jurnal Akuntansi Universitas Udayana 11.3, 713729. 
Mulyadi. (2017). Auditing (edisi 6). Jakarta: Salemba Empat.

Ni Wayan Lesya Pratiwi. (2018). "Pengaruh Pergantian Manajemen, Opini Going Concern, dan Tingkat Pertumbuhan Perusahaan Terhadap Auditor switching Studi Kasus pada Perusahaan Sektor Keuangan yang Terdaftar di Bursa Efek Indonesia Tahun 2014-2017". Skripsi. Denpasar: Universitas Pendidikan Nasional.

Prof. Dr. Abdul Halim, M.B.A. (2015). Auditing (edisi 5). UPP STIM YKPN.

Sugiyono. (2018). Metodologi Penelitian Kuantitatif, Kualitatif, dan R\&D. Bandung: CV Alfabeta.

Sukrisno Agoes. (2017). Auditing Petunjuk Praktis Pemeriksaan Akuntan oleh Akuntan Publik (buku 1, edisi 6). Jakarta: Salemba Empat.

Suprapto Pasaribu. (2017). "Pengaruh Financial Distress, Opini Audit, Audit delay dan Biaya Audit Terhadap Auditor switching pada Perusahaan Manufaktur Terbuka (Tbk) yang Terdaftar di BEI Tahun 2013-2016". Skripsi. Medan: Universitas Sumatera Utara. 